\title{
Halogenated furanones inhibit quorum sensing through accelerated LuxR turnover
}

\author{
Michael Manefield, ${ }^{1,2}$ Thomas Bovbjerg Rasmussen, ${ }^{2}$ Morten Henzter, ${ }^{2}$ \\ Jens Bo Andersen, ${ }^{2}$ Peter Steinberg, ${ }^{3}$ Staffan Kjelleberg ${ }^{1,3}$ \\ and Michael Givskov ${ }^{2}$
}

Author for correspondence: Michael Givskov. Tel: +45 45252769. Fax: + 4545932809. e-mail:immg@pop.dtu.dk

\footnotetext{
1 School of Microbiology and Immunology, University of New South Wales, Sydney, Australia

2 Department of Microbiology, Technical University of Denmark, 2800 Lyngby, Denmark

3 Centre for Marine Biofouling and BioInnovation, University of New South Wales, Sydney, Australia
}

\begin{abstract}
$\mathrm{N}$-acyl-L-homoserine lactones (AHLs) are co-regulatory ligands required for control of the expression of genes encoding virulence traits in many Gramnegative bacterial species. Recent studies have indicated that AHLs modulate the cellular concentrations of LuxR-type regulatory proteins by binding and fortifying these proteins against proteolytic degradation (Zhu \& Winans, 2001). Halogenated furanones produced by the macroalga Delisea pulchra inhibit AHL-dependent gene expression. This study assayed for an in vivo interaction between a tritiated halogenated furanone and the LuxR protein of Vibrio fischeri overproduced in Escherichia coli. Whilst a stable interaction between the algal metabolite and the bacterial protein was not found, it was noted by Western analysis that the half-life of the protein is reduced up to 100 -fold in the presence of halogenated furanones. This suggests that halogenated furanones modulate LuxR activity but act to destabilize, rather than protect, the AHL-dependent transcriptional activator. The furanone-dependent reduction in the cellular concentration of the LuxR protein was associated with a reduction in expression of a plasmid encoded $P_{\text {luxi }}-g f p$ (ASV) fusion suggesting that the reduction in LuxR concentration is the mechanism by which furanones control expression of AHL-dependent phenotypes. The mode of action by which halogenated furanones reduce cellular concentrations of the LuxR protein remains to be characterized.
\end{abstract}

Keywords: Delisea pulchra, homoserine lactone, intercellular signal

\section{INTRODUCTION}

Many Gram-negative bacterial species employ $\mathrm{N}$-acyl-Lhomoserine lactones (AHLs) to control the synthesis of products that facilitate interactions with the surrounding environment, including interactions with eukaryotic host species (reviewed by Eberl, 1999; Kievit \& Iglewski, 2000). AHL dependent gene expression has been suggested to constitute a mechanism by which bacteria can alter their behaviour in response to cell density and is thus commonly referred to as quorum sensing (reviewed by Swift et al., 1999).

The diverse range of AHL regulated phenotypes includes the production of degradative extracellular enzymes by

Abbreviations: $\mathrm{AHL}, \mathrm{N}$-acyl-L-homoserine lactone; 3-oxo-C6-HSL, $\mathrm{N}$-3oxo-hexanoyl-homoserine lactone; RFU, relative fluorescence unit.
Pseudomonas aeruginosa and Erwinia carotovora (Jones et al., 1993), bioluminescence in Vibrio fischeri (Sitnikov et al., 1995) and Vibrio harveyi (Bassler et al., 1993), plasmid transfer in Agrobacterium tumefaciens (Piper et al., 1993), antibiotic production in E. carotovora (Bainton et al., 1992), and more complex phenotypes such as surface motility in Serratia liquefaciens (Eberl et al., 1999) and development of biofilm architecture in P. aeruginosa (Davies et al., 1998)

AHLs are synthesized by homologues from either the AinS or LuxI family of AHL synthases and mediate transcription of various target genes through an interaction with, in most cases, a homologue of the LuxR protein of V. fischeri (reviewed by Fuqua et al., 1996). AHLs show variation in the length, degree of saturation and adjoining substitutions of the acyl chain (reviewed by Fuqua \& Eberhard, 1999). These structural variations account for the different responses elicited by different 
AHLs in quorum sensing assays (McClean et al., 1997; Zhu et al., 1998). The molecular mechanism by which AHLs trigger the transcriptional activation of target promoters via an interaction with LuxR homologues remains to be fully elucidated (see Discussion), but appears to involve AHL binding to and induction of conformational changes in the regulatory protein which lead to multimerization and DNA binding (Choi \& Greenberg, 1992; Qin et al., 2000; Welch et al., 2000). Other cellular components are involved in the expression of AHL-regulated genes including the cAMP receptor protein (Nealson et al., 1972), the H-NS protein (Ulitzur et al., 1997), and the molecular chaperones GroES and GroEL (Adar et al., 1992).

The discovery of quorum sensing has afforded a novel opportunity to control unwanted microbial activity without the use of growth inhibitory agents such as antibiotics, preservatives and disinfectants that select for resistant organisms. A means of interfering with AHL-mediated gene expression not only has potential in a number of applied contexts, including the treatment of lung infections in cystic fibrosis patients, but would also constitute an evolutionary advantage for plant and animal species under selective pressure from quorum sensing pathogens.

Gram-negative bacteria engage in AHL-dependent phytopathogenic (Barras et al., 1994; Zhang et al., 1993) and phytosymbiotic (Rodelas et al., 1999) relationships with terrestrial plants. Whilst there are no known examples of such relationships in the marine environment, marine plants are at once rich in secondary metabolite chemistry and, in the absence of more advanced immune systems, prone to disease (Correa, 1996; Fenical, 1997). For these reasons marine plants are likely candidates for the evolution of AHL antagonist activity (Kjelleberg \& Steinberg, 2001). The marine macroalga Delisea pulchra produces a range of lactones, known more specifically as halogenated furanones, which inhibit quorum sensing (Givskov et al., 1996; Manefield et al., 1999; Rasmussen et al., 2000). It has previously been proposed that the production of the halogenated furanones in specialized cells, which migrate to the surface of the alga to release the compounds (Dworjanyn et al., 1999), is likely to have evolved in response to the negative impacts of AHL-dependent colonization of its surfaces by marine bacterial species (Givskov et al., 1996; Kjelleberg et al., 1997; Kjelleberg \& Steinberg, 2001).

It has been demonstrated that halogenated furanones have inhibitory effects in a variety of biological assays designed to measure AHL-mediated gene expression (Givskov et al., 1996). Such inhibition was found to be partially relieved by increasing AHL concentrations in the bioasssays, indicative of competition for a regulatory function (Manefield et al., 1999). Furthermore, halogenated furanones were found to have activity in an in vivo ligand-binding assay employed to monitor the displacement of AHLs from the LuxR protein (Manefield et al., 1999). These results have been in accordance with a model in which halogenated furanones compete with AHLs for a common binding site on LuxR and LuxR homologues. In this study we tested directly for an interaction between a halogenated furanone and the LuxR protein, and discovered that the furanones inhibit AHL-mediated gene expression through accelerated degradation of the transcriptional activator.

\section{METHODS}

Strains, plasmids and culture conditions. The LuxR overproduction strain Escherichia coli XL-1 Blue(pHK724) (pGroESL) and the control strain E. coli XL-1 Blue(pGroESL) were cultured and washed during assays in Luria-Bertani broth (containing $10 \mathrm{~g} \mathrm{NaCl} \mathrm{l}^{-1}$ ). Plasmid pHK724 carries a $P_{\text {tac }}-l u x R$ fusion and encodes resistance to $50 \mu \mathrm{g}$ ampicillin $\mathrm{ml}^{-1}$ (Hanzelka \& Greenberg, 1995). Plasmid pGroESL carries $P_{1 a c}-$ groES and $P_{\text {lac }}-$ groEL fusions and encodes resistance to $25 \mu \mathrm{g}$ chloramphenicol $\mathrm{ml}^{-1}$ (Goloubinoff et al., 1989). The LuxR-based green fluorescent AHL monitor strain E. coli MT102(pJBA89) was cultured and diluted during assays in minimal ABT medium $\left[\left(\mathrm{NH}_{4}\right)_{2} \mathrm{SO}_{4}, 15 \cdot 1 \mathrm{mM} ; \mathrm{Na}_{2} \mathrm{HPO}_{4}\right.$. $2 \mathrm{H}_{2} \mathrm{O}, 33.7 \mathrm{mM} ; \mathrm{KH}_{2} \mathrm{PO}_{4}, 22.0 \mathrm{mM} ; \mathrm{NaCl}, 51.0 \mathrm{mM}$; $\mathrm{MgCl}_{2} .6 \mathrm{H}_{2} \mathrm{O}, 1.0 \mathrm{mM} ; \mathrm{CaCl}_{2}, 0.1 \mathrm{mM} ; \mathrm{FeCl}_{3}, 10 \mu \mathrm{M}$; thiamin, $7 \cdot 4 \mu \mathrm{M}$ ] (Clark \& Maaløe, 1967) supplemented with $0.5 \%$ glucose and $0.5 \%$ Casamino acids. Plasmid pJBA89 carries $l u x R$ and $P_{\text {luxi }}-g f p$ (ASV) fusion and encodes resistance to $50 \mu \mathrm{g}$ ampicillin $\mathrm{ml}^{-1}$ (Andersen et al., 2001). The clp lon double mutant E. coli KY2347 [MG1655 $\Delta$ (clpPX-lon) 1196::cat] (Zhu \& Winans, 2001) and the isogenic parent $E$. coli MG1655 (wild-type E. coli K-12 ilvG rph-1) (Guyer et al., 1981), both harbouring pJBA89, were cultured in LB diluted 20 times in ABT medium. Unless otherwise stated, the relevant antibiotics at the above-mentioned concentrations were included in cultures to ensure plasmid maintenance.

AHL and furanone preparation. Synthetic N-oxohexanoyl-Lhomoserine lactone was prepared according to the method of Eberhard et al. (1981) and stored in ethyl acetate at $20 \mathrm{mg} \mathrm{ml}^{-1}$ (approx. $100 \mu \mathrm{M}$, depending on the compound) at $-20^{\circ} \mathrm{C}$ in a non-frost free freezer. The halogenated furanones compound 2, compound 8 and compound 56 were synthesized as previously described by Manny et al. (1997). Compound 4 was extracted from D. pulchra and purified by HPLC according to protocols established by de Nys et al. (1993). Compound 30 was synthesized according to protocols reported by Wells (1963). Tritiated compound 4 was prepared by reducing a ketone group at the $\mathrm{C}\left(1^{\prime}\right)$ position on the alkyl chain of a compound 4 precursor with tritiated borane producing an enantiomeric mixture of the $\mathrm{S}$ and $\mathrm{R}$ forms of compound 4 with a tritium atom replacing the hydrogen atom at the $\mathrm{C}\left(1^{\prime}\right)$ position. The furanones were stored in ethanol at $20 \mathrm{mg} \mathrm{ml}^{-1}$ at $-20{ }^{\circ} \mathrm{C}$ in a non-frost free freezer.

Binding analysis. A variation on the method of Hanzelka \& Greenberg (1995) was employed to assay for an in vivo affinity between the LuxR protein and ${ }^{3} \mathrm{H}$-labelled compound 4. LuxR, GroES and GroEL overproduction was induced in exponential phase E. coli XL-1 Blue(pHK724)(pGroESL) and E. coli XL-1 Blue(pGroESL) cultures $\left(\mathrm{OD}_{600} 0 \cdot 3\right)$ by incubation with $100 \mu \mathrm{M}$ IPTG for $2 \mathrm{~h}$. Various concentrations of the labelled halogenated furanone were then added to $1 \mathrm{ml}$ aliquots of the induced cultures. After $10 \mathrm{~min}$ incubation, the cells were washed, resuspended in scintillation fluid and monitored for tritium as previously described for ${ }^{3} \mathrm{H}-3$-oxoC6-HSL (Manefield et al., 1999; Hanzelka \& Greenberg, 1995). A standard curve describing the relationship between 
the quantity of the labelled furanone and its relative activity in c.p.m., obtained by diluting known amounts of ${ }^{3} \mathrm{H}$-labelled compound 4 in $100 \mu \mathrm{l}$ scintillation fluid, was used to convert the raw data obtained from c.p.m. to nmol.

Determination of GFP expression. The effect of halogenated furanones on expression of a 3-oxo-C6-HSL stimulated, LuxR controlled $P_{\text {lux I }}-g f p$ (ASV) fusion [encoding an unstable Gfp protein with half life ranging from $40 \mathrm{~min}$ to $110 \mathrm{~min}$ in exponential and stationary phase cells, respectively (Andersen et al., 1998, 2001)] was determined as follows. Aliquots (200 $\mu \mathrm{l}$ ) of exponential phase E. coli MT102(pJBA89) cultures were distributed to the wells of microtitre dishes in which 3oxo-C6-HSL and furanone compounds in the required concentrations were already present. After $2 \mathrm{~h}$ incubation at $37^{\circ} \mathrm{C}$ the relative fluorescence units (RFU) of each sample were captured with a Wallac Victor2, I420 Multilabel Counter using a $485 \mathrm{~nm}$ excitation filter and a $535 \mathrm{~nm}$ emission filter. The $\mathrm{OD}_{450}$ was also determined for each sample to monitor growth of the bacterial strain.

LuxR Western analysis. E. coli XL-1 Blue(pHK724)(pGroESL) was grown in the presence of $100 \mu \mathrm{M}$ IPTG to OD $_{600} 0 \cdot 3$. Cells were harvested by centrifugation at $10000 \mathrm{~g}, 4{ }^{\circ} \mathrm{C}$ for $5 \mathrm{~min}$ and resuspended in an equal volume of fresh media. The washed culture was split into $5 \mathrm{ml}$ aliquots and treated with various concentrations of halogenated furanones and/ or 3-oxo-C6-HSL (N-3-oxo-hexanoyl-homoserine lactone). Samples were taken over time for determination of optical density and for Western analysis. Samples taken for Western analysis were frozen immediately and kept at $-20{ }^{\circ} \mathrm{C}$. Prior to SDS-gel electrophoresis, the samples were adjusted to the same absorbance. Western analysis of the separated proteins was performed using an anti-LuxR antibody from Quorum Sciences as the primary antibody and an anti-rabbit horseradish peroxidase conjugated antibody from Amersham Pharmacia Biotech as the secondary antibody, according to the manufacturers recommendations. Localization of the secondary antibody was visualized using chemiluminescent detection reagents from Amersham Pharmacia Biotech and a Hamamatsu C2400-47 double intensified CCD camera (Hamamatsu). Colour images were saved in 16-bit format (the scale has a resolution of 16 colours) using ARGUS-50 software (Hamamatsu). The relative amounts of LuxR protein in each sample were estimated from a standard curve relating colour to relative LuxR content constructed from a two-fold dilution series of fully IPTG induced cells. Prior to SDSgel electrophoresis, the samples were adjusted to the same absorbance.

To assess whether the translation of persistent $\operatorname{lu} x \mathrm{R}$ mRNA during the above described treatment contributed to the cellular pool of LuxR measured in the Western procedure, $100 \mu \mathrm{g}$ chloramphenicol $\mathrm{ml}^{-1}$ was administered after the removal of IPTG, just prior to furanone treatment, to disrupt the ribosomal activity required for LuxR production. Cells treated thus were assessed by Western blotting as above.

\section{RESULTS}

\section{Assaying LuxR affinity for a halogenated furanone}

To further explore the hypothesis that halogenated furanones have affinity for the LuxR protein, it was of interest to test directly for an interaction between the protein and the algal metabolites and, if possible, to ascertain whether a correlation exists between binding activity and biological activity in bioassays. Because the LuxR protein has never been isolated with AHL-binding

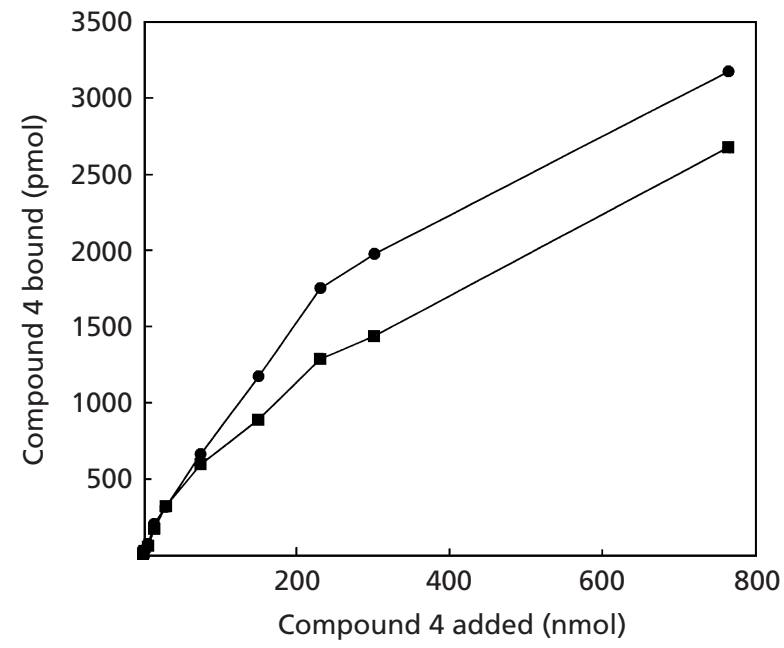

Fig. 1. Dose response relationship for ${ }^{3} \mathrm{H}$-labelled compound 4 binding to XL-1 Blue(pHK724)(pGroESL) (O) and XL-1 Blue (pGroESL) ( $\boldsymbol{\square}) .{ }^{3} \mathrm{H}$-labelled compound $4(0-800 \mathrm{nmol})$ was added to $1 \mathrm{ml}$ aliquots of each culture and incubated for $10 \mathrm{~min}$. The cultures were then washed several times before assaying for the tritium signal using a scintillation counter. Radioactivity was related to ${ }^{3} \mathrm{H}$-labelled compound 4 concentration by a standard curve. These data are representative of two separate experiments in which treatments were performed in duplicate.

activity we employed the in vivo approach used to demonstrate 3-oxo-C6-HSL binding activity in the LuxR protein overproduced in E. coli (Hanzelka \& Greenberg, 1995). To this end tritium-labelled compound 4 was synthesized (see Methods) and incorporated at various concentrations (0-800 nmol) into $1 \mathrm{ml}$ aliquots of XL-1 Blue(pHK724)(pGroESL) and XL-1 Blue(pGroESL) cultures overproducing LuxR and GroESL or GroESL alone, respectively. The concurrent overproduction of the molecular chaperones GroES and GroEL with LuxR enhances the affinity of the native AHL ligand for the overproducing cells (Hanzelka \& Greenberg, 1995). After a short incubation, cells were washed and assayed for the quantity of ${ }^{3} \mathrm{H}$-labelled compound 4 retained.

Fig. 1 describes the dose response relationships obtained for the two strains. The E. coli culture overproducing the LuxR protein retained between $0.4 \%$ and $1.5 \%$ of the tritiated furanone added, depending on the concentration added. By comparison, the control culture overproducing the chaperone proteins alone retained from $0.4 \%$ to $1.1 \%$ of the labelled compound added. Whilst this small difference may represent an association between the algal metabolite and the LuxR protein, these results suggest that any LuxR-compound 4 complex formed is unstable in nature.

\section{Halogenated furanones induce instability of the LuxR protein}

To resolve the apparent paradox in the observation that halogenated furanones do not form a stable complex with the LuxR protein but can displace 3-oxo-C6-HSL 
(a)

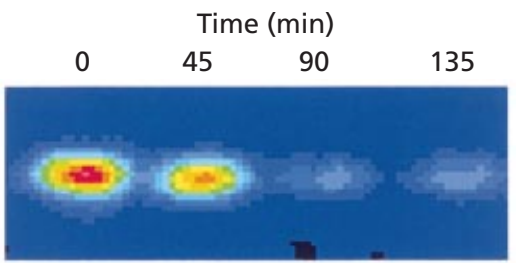

(b)

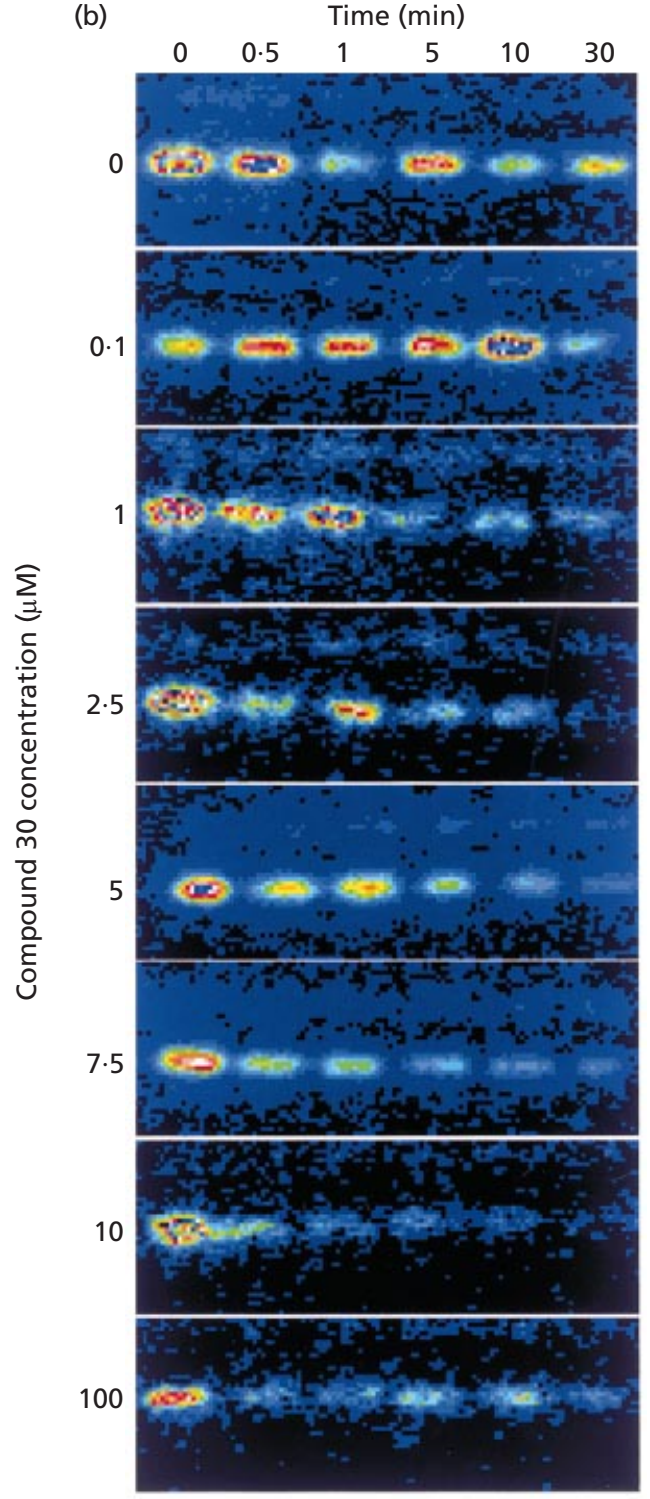

Fig. 2. Western blots following the decay of the LuxR protein over time in the absence and presence of compound 30. (a) An E. coli XL-1 Blue(pHK724)(pGroESL) culture was stimulated to produce LuxR with $100 \mu \mathrm{M}$ IPTG and washed with fresh media. The culture was sampled after 0, 45, 90 and 135 min and analysed by Western blotting employing a LuxR antibody. (b) Cultures were stimulated to produce LuxR, washed as in (a) and split into eight subcultures which were treated with various compound 30 concentrations $(0 \cdot 1-100 \mu \mathrm{M})$. Samples were removed after $0,0 \cdot 5$, $1,5,10$ and $30 \mathrm{~min}$, and analysed as in (a). These blots are representative of three separate experiments. The colours reflect intensity of the band, which correlates with protein quantity. The highest band intensity is represented by white pixels with red, green, yellow and blue pixels representing decreasing intensity, respectively. from LuxR (Manefield et al., 1999), we hypothesized that binding of halogenated furanones to LuxR accelerates the proteolytic degradation of the protein. Since AHL-regulated phenotypes are not expressed in the absence of LuxR-type regulatory proteins, the data presented here could be reconciled with that published previously if the presence of halogenated furanones affected the steady-state cellular concentration of functional LuxR protein.

To address this hypothesis we examined the amounts of LuxR protein in cells treated with furanones. To assess the in vivo stability of LuxR, XL-1 Blue(pHK724) (pGroESL) cells were induced with $100 \mu \mathrm{M}$ IPTG, washed free of the inducer and sampled at different time points after the wash. The amounts of LuxR protein in the different samples were then visualized by an SDSPAGE-Western blot procedure using LuxR antibody and a chemiluminescence-based detection system. A CCD camera reported chemiluminescence as colour digital images with increasingly lighter colours relating to increases in band intensity (Fig. 2a).

A correlation between the coloured intensity scale and the relative amount of LuxR protein was established with a twofold serial dilution of a LuxR preparation (data not shown), revealing that the synthesized LuxR protein decayed with a half-life of approximately $65 \mathrm{~min}$ (Fig. 2a). Indistinguishable results were obtained in the presence and absence of $100 \mu \mathrm{g}$ chloramphenicol ml $\mathrm{m}^{-1}$ indicating that translation of the $\operatorname{luxR}$ transcript does not contribute to the cellular pool of LuxR protein after removal of the $P_{\text {tac }}$ inducer. LuxR had a comparable, perhaps marginally longer half-life in the presence of $2 \mu \mathrm{M}$ 3-oxo-C6-HSL (data not shown). When IPTG induced XL-1 Blue(pHK724)(pGroESL) cells were washed free of IPTG and then exposed to a synthetic halogenated furanone with strong inhibitory activity in a LuxR-dependent GFP-based AHL bioassay (compound 30), it was obvious from the Western analysis that LuxR levels decreased much faster. This indicated that the halogenated furanone promoted turnover of the LuxR protein. The half-life of LuxR was found to decrease with increasing concentrations of compound 30 (Fig. 2b).

\section{A correlation between furanone activity, cellular LuxR concentration and expression of the luxI promoter}

To determine whether furanone-dependent decay of the LuxR protein was the mechanism by which halogenated furanones inhibit expression from the promoter of the luxI gene $\left(P_{\text {luxI }}\right)$ we assessed the relationship between furanone activity, cellular LuxR concentration and $P_{\text {luxi }}$ expression. We tested a series of compounds (Table 1) for their ability to inhibit 3-oxo-C6-HSL-induced LuxRdependent expression of fluorescence from a $P_{\text {luxi }}-g f p$ (ASV) fusion in the AHL monitor strain E. coli MT102(pJBA89). The effect of two natural and three synthetic halogenated furanones (Table 1) on 3-oxo-C6HSL stimulated $\operatorname{LuxR} P_{\text {luxI }}-g f p$ (ASV) expression was 
Table 1. The structures and inhibition indexes of various halogenated furanones

\begin{tabular}{|c|c|c|}
\hline $\begin{array}{c}\text { Compound } \\
\text { no. }\end{array}$ & Structure & $\begin{array}{c}\text { Inhibition } \\
\text { index* }\end{array}$ \\
\hline 2 & & 0.47 \\
\hline 4 & & 0.26 \\
\hline 8 & & 0.76 \\
\hline 30 & & $0 \cdot 16$ \\
\hline 56 & & 0.48 \\
\hline
\end{tabular}

* A low inhibition index indicates strong biological activity (see text for details).

determined at eight different furanone concentrations (ranging from 0 to $40 \mu \mathrm{M}$ ) and three different 3-oxo-C6HSL concentrations (ranging from 25 to $100 \mathrm{nM}$ ). Incubation with $100 \mathrm{nM} 3$-oxo-C6-HSL and no furanone addition was defined as having $100 \%$ RFU. A total of $24 \mathrm{RFU}$ values obtained for each furanone compound were used to calculate an inhibition index expressing the quantity of furanone $(\mu \mathrm{mol})$ per quantity of 3-oxo-C6HSL (nmol) required to inhibit $P_{\text {luxI }}-g f p($ ASV) expression to an arbitrary level $(40 \%)$. This is termed the $\mathrm{ID}_{40}$ value. The three values obtained, one for each 3-oxoC6-HSL concentration, were plotted as a function of 3oxo-C6-HSL concentration (illustrated for compound 30 in Fig. 3) and the gradient of the best straight line passing through the origin was taken as the inhibition index $\left(\mathrm{IIX}_{40}\right)$. The IIX $\mathrm{I}_{40}$ expresses the number of moles furanone per mmole 3-oxo-C6-HSL required to inhibit expression of fluorescence to $40 \%$ of the untreated

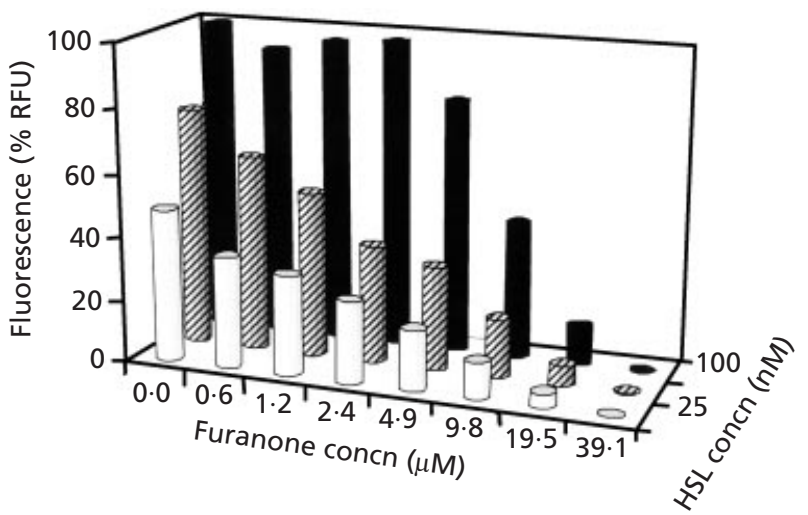

Fig. 3. Determination of $I I X_{40}$ for compound 30. 3-oxo-C6-HSLstimulated $L$ Lux $P_{\text {luxl }}-g f p$ (ASV) fluorescence (y axis) was determined at eight different furanone ( $x$ axis) and three different 3-oxo-C6-HSL concentrations (z axis). Incubation with $100 \mathrm{nM}$ 3-oxo-C6-HSL and no furanone addition was defined as having $100 \%$ RFU. ID 40 values (one for each 3-oxo-C6-HSL concentration) were determined as described in the text.

sample. A low $\operatorname{IIX}_{40}$ value therefore indicates that a compound is an efficient quorum-sensing inhibitor. Using this method, it was found that the most active compounds tested are compounds 30 (synthetic) and 4 (natural). Compounds 2 (natural) and 56 (synthetic) have medium activity whereas compound 8 (synthetic) has poor activity (Table 1).

The range of inhibitory activities displayed provided an opportunity to relate this activity to the degradation of LuxR. We therefore assessed the effect of each compound on the stability of LuxR. IPTG-induced XL-1 Blue(pHK724)(pGroESL) cells were washed free of IPTG, treated with $50 \mu \mathrm{M}$ compound $2,4,8,30$ or 56 and sampled for Western analysis. As shown in Fig. 4, treatment with compound 8 (inhibition index of 0.76 ) did not decrease the LuxR half-life compared to the untreated samples. Samples treated with compound 2 (inhibition index of 0.47), compound 4 (inhibition index of 0.26 ) and compound 56 (inhibition index of 0.48 ) accelerated the LuxR turnover when compared to the untreated control. The limited resolution of the assay failed to reproducibly distinguish between the activity of these three compounds. Finally, compound 30 (inhibition index of $0 \cdot 16$ ) had the greatest impact on LuxR turnover compared to the other treatments. These results supported a correlation between furanone activity, LuxR concentration and $P_{\text {luxi }}-g f p(\mathrm{ASV})$ expression.

Finally, to confirm the relationship between the furanone-induced decreases in fluorescence expression from the LuxR-controlled $P_{\text {luxi }}-g f p(\mathrm{ASV})$ fusion and the furanone-accelerated turnover of the LuxR protein, we assayed samples of E. coli MT102(pJBA89) cultures treated with $100 \mathrm{nM} 3$-oxo-C6-HSL and 0, 0.5, 1, 5 or $10 \mu \mathrm{M}$ compound 30 for fluorescence every $10 \mathrm{~min}$. When distinct differences between the fluorescence 


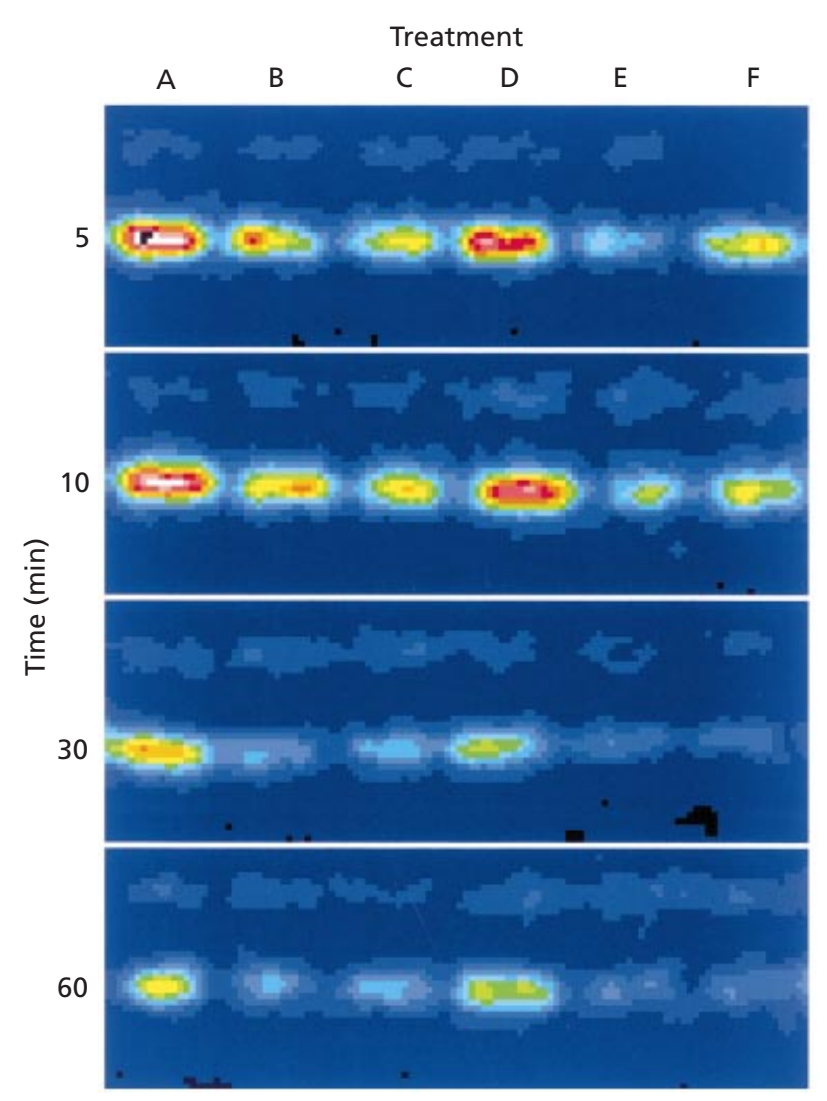

Fig. 4. Western blots comparing the rate of decay of the LuxR protein in XL-1 Blue(pHK724)(pGroESL) cultures treated with different halogenated furanones $(50 \mu \mathrm{M})$. Treatments are: $A$, an untreated negative control; $\mathrm{B}, 50 \mu \mathrm{M}$ compound 2; $\mathrm{C}, 50 \mu \mathrm{M}$ compound 4; $\mathrm{D}, 50 \mu \mathrm{M}$ compound $8 ; \mathrm{E}, 50 \mu \mathrm{M}$ compound 30 ; and $\mathrm{F}, 50 \mu \mathrm{M}$ compound 56 . The relative effect of each compound on the half-life of the LuxR protein corresponds with the activity of each in the LuxR-based GFP assays. These blots are representative of two separate experiments.

signal from the various treatments were apparent (90 min after furanone addition) samples were assayed for LuxR levels by means of Western blotting. Fig. 5 illustrates the correlation between decreases in LuxR levels and decreases in fluorescence. It was apparent that incremental decreases in the fluorescence levels associated with increasing compound 30 concentrations are concurrent with the loss of the LuxR protein.

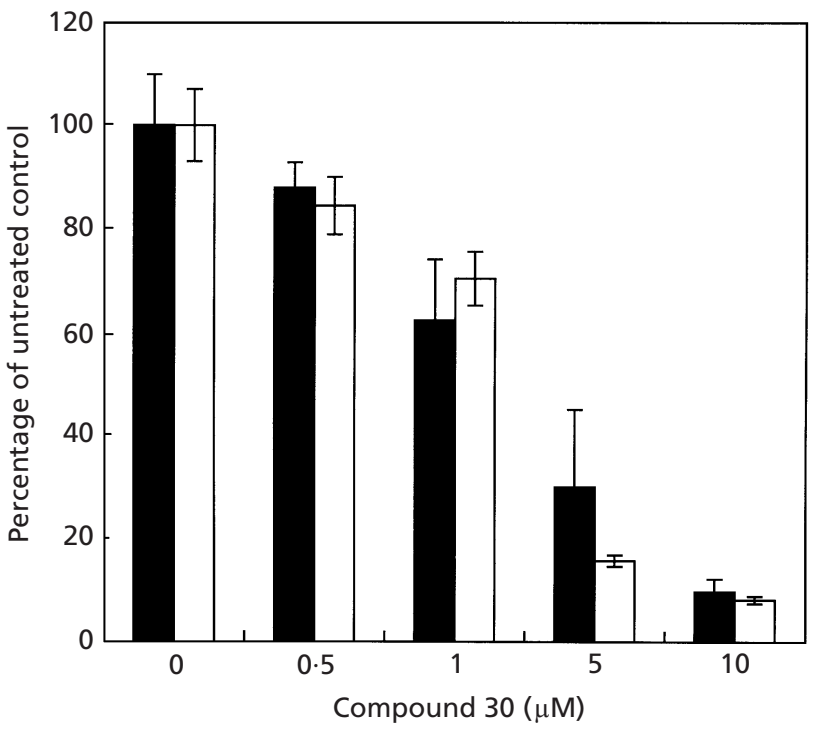

Fig. 5. Correlation between changes in GFP expression and LuxR concentration. MT102(pJBA89) cultures treated with 100 nM 3-oxo-C6-HSL and various concentrations of compound 30 were sampled in triplicate for GFP activity and the quantity of LuxR. The specific GFP activity (RFU/OD ${ }_{600}$ )(black bars) and the relative LuxR quantity (white bars) of the negative control culture (treated with 3-oxo-C6-HSL only) were arbitrarily set to 1. This graph is representative of two separate experiments. Error bars represent standard deviation.

\section{Furanone-promoted degradation of LuxR is protease independent}

Comparable results were obtained when the above experiments were conducted in a $c l p P$ strain and in a lon strain. In both cases activity was tested [LuxR controlled $\left.P_{\text {luxi }}-g f p(\mathrm{ASV})\right]$ and protein half-life was investigated (data not shown). This indicated that neither the $c_{p P}$ protease nor the lon protease affected stability of the LuxR protein. We therefore tested expression of Gfp from pJBA89 in a clp lon background as well as in the isogenic $c p^{+}$lon $^{+}$parent. Strains KY2347 and MG1655 grew more slowly than our preferred MT102 strain. In MG1655 the IIX ${ }_{40}$ value for compound 30 was found to be 0.23 (compared to 0.16 in MT102). In the KY2347 (clp lon) the IIX ${ }_{40}$ value for compound 30 was found to be $0 \cdot 34$.

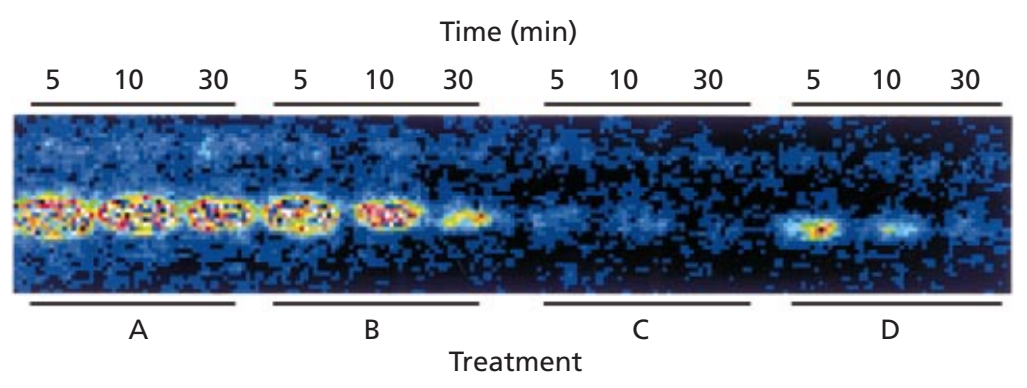

Fig. 6. Western blot following the decay of the LuxR protein over time (5-30 $\mathrm{min}$ ) in XL1 Blue(pHK724)(pGroESL) cultures in the presence and absence of 3-oxo-C6-HSL and compound 30 . Treatments are: $A$, an untreated negative control; $\mathrm{B}, 2 \mu \mathrm{M}$ 3-oxo-C6-HSL; C, $10 \mu \mathrm{M}$ compound $30+2 \mu \mathrm{M}$ 3-oxo-C6-HSL (in that order); and D, $2 \mu \mathrm{M}$ 3-oxo-C6-HSL+ $10 \mu \mathrm{M}$ compound 30 (in that order). Addition of 3-oxo-C6-HSL prior to treatment with the halogenated furanone protects the protein from degradation. This blot is representative of three separate experiments. 


\section{The presence of 3-oxo-C6-HSL protects the LuxR} protein against furanone promoted degradation

Whilst analysing the expression of the LuxR controlled $P_{\text {lux }}-g f p$ (ASV) fusion we realized that increasing 3-oxoC6-HSL concentrations reduced the inhibitory activity of the furanones on the fluorescence phenotype (data not shown). To assess whether this was a manifestation of the protection of LuxR by 3-oxo-C6-HSL we tested the effect of the AHL on compound 30 induced LuxR decay. Fig. 6 (c) illustrates that the addition of $2 \mu \mathrm{M} 3-$ oxo-C6-HSL approximately $60 \mathrm{~s}$ after the addition of $10 \mu \mathrm{M}$ compound 30 did not afford LuxR any protection from furanone-induced degradation. Fig. 6 (d) however, illustrates that if $2 \mu \mathrm{M} 3$-oxo-C6-HSL was added $60 \mathrm{~s}$ prior to the addition of $10 \mu \mathrm{M}$ compound 30, the furanone-induced degradation was retarded by at least $10 \mathrm{~min}$. Note that in the fluorescence assay employed to calculate the inhibition index for each compound, halogenated furanones and 3-oxo-C6-HSL were added simultaneously.

These data indicate that once compound 30 induced degradation of the LuxR protein is initiated, presumably through a direct interaction between the compound and the protein, it is not reversible by addition of 3-oxo-C6HSL. However, prior addition of 3-oxo-C6-HSL offers some protection to LuxR from compound 30.

\section{DISCUSSION}

From the few biochemical studies that have been performed on the function of LuxR-type regulatory proteins, a model of how AHLs cause transcription of specific genes is beginning to emerge (Zhu \& Winans, 2001; Welch et al., 2000; Qin et al., 2000; Zhu \& Winans, 1999). In vitro investigations with the CarR protein of E. carotovora and the TraR protein of $A$. tumefaciens, including DNA bandshift, fluorescence quenching and tryptic digestion experiments, have revealed that cognate AHLs directly interact with and induce conformational changes in these regulatory proteins (Zhu \& Winans, 2001; Welch et al., 2000). What remains uncertain is the effect these conformational changes have on the behaviour of the protein.

Qin et al. (2000) have proposed a model in which the TraR protein is monomeric and membrane associated in the absence of 3-oxo-C8-HSL but dimeric, cytoplasmic and capable of transcriptional activation in its presence. Zhu \& Winans (2001) have recently presented another model in which the TraR protein is monomeric and vulnerable to proteolysis in the absence of 3-oxo-C6HSL but dimeric, resistant to proteolysis and capable of transcriptional activation in its presence. These models both draw attention to the relevance of the cytoplasmic concentration of $\mathrm{TraR}$ in the activation of target promoters.

In the present communication we have sought to further define the molecular mechanism by which halogenated furanones inhibit the AHL-mediated transcriptional activation of target genes. We have been unable to detect the formation of a stable complex between a tritiated halogenated furanone and the LuxR protein overproduced in E. coli. We have however demonstrated that the cytoplasmic concentration of the LuxR protein is decreased in the presence of halogenated furanones. In the light of both these results and the demonstration that 3-oxo-C8-HSL protects the TraR protein in E. coli from proteolytic digestion (Zhu \& Winans, 2001) it is suggested that halogenated furanones interact with the LuxR protein but that this interaction causes conformational changes that enlist the furanone-LuxR complex into rapid proteolytic degradation. This model is consistent both with the observed effects of furanones on the formation of the AHL-LuxR complex (Manefield et al., 1999) and with the inability to detect a long-lived furanone-LuxR complex.

Is the loss of LuxR the result of proteolytic degradation? The effect of furanones on the LuxR concentration was comparable in a wild-type E. coli strain and a $c l p P$ and a lon E. coli strain. Zhu \& Winans (2001) found that a substantial change in the rate of TraR degradation in $E$. coli required the simultaneous crippling of both the $c l p$ and lon proteases. We found no significant change in the inhibition index for compound 30 in the different strains. This indicated that not even the Clp and Lon proteases in concert could severely affect the LuxR stability. This however, does not rule out the possibility that other proteases could be involved in the proteolytic turnover of LuxR. The possibility that the LuxR protein becomes compartmentalized in a manner analogous to the proposal of Qin et al. (2000) in the presence of the furanones is unlikely given that whole cells (i.e. including membranes) were used in the Western procedure employed here.

We did not reproducibly detect an increase in LuxR stability in the presence of 3-oxo-C6-HSL as was demonstrated by Zhu \& Winans (2001) for the TraR protein in the presence of 3-oxo-C8-HSL. In our experiments however 3-oxo-C6-HSL was always added after the cessation of stimulation of the $\operatorname{lux} R$ promoter (i.e. after removal of IPTG). Zhu \& Winans (2001) found that the AHL-induced protection of TraR was dependent on the presence of 3-oxo-C8-HSL during synthesis of the protein and that addition of 3-oxo-C8HSL to E. coli cells already harbouring the TraR monomer did not afford the protein any protection against proteolysis. Our observations with LuxR are therefore not inconsistent with those of Zhu \& Winans (2001).

The ability of 3-oxo-C6-HSL to protect the LuxR protein from furanone-induced degradation was dependent on the addition of the AHL before the furanone. This result suggests that, unlike 3-oxo-C8-HSL and TraR, 3-oxo-C6-HSL binds mature LuxR and that in this state the halogenated furanones are less able to compete for the AHL binding site. It is possible that 3oxo-C6-HSL is binding and protecting low levels of freshly translated LuxR from persistent luxR mRNA transcript. However, the addition of chloramphenicol to block translation after cessation of transcription did not 
affect LuxR levels, indicating that residual translation was not occurring. Either way it is clear that 3-oxo-C6HSL can protect the LuxR protein from furanoneinduced degradation when present before the furanone, but is unable to rescue the protein if the furanone is present first and has already initiated degradation.

The superior activity of compounds lacking a carbon chain extending from the furan ring structure in the control of both $P_{\text {luxi }}-g f p$ (ASV) expression and LuxR concentration was somewhat unexpected because the homoserine lactone ring without the acyl chain has been shown not to interact with the LuxR homologue CarR (Welch et al., 2000). The significance of this will remain unresolved until more structural information regarding LuxR homologues and their AHL binding sites is available.

AHLs are required for the expression of Gram-negative bacterial phenotypes involved in many cases in an interaction with a higher organism. Amongst some of the best studied examples, including elastase production in $P$. aeruginosa, pectate lyase production in E. carotovora and conjugation of the plant-tumour-inducing $\mathrm{Ti}$ plasmid of A.tumefaciens, are behaviours with central roles in the success of bacterial infections of medical, agricultural and therefore economic significance. This investigation has demonstrated that halogenated furanones produced naturally by the marine alga $D$. pulchra can modulate the cellular concentration of the LuxR protein responsible for the reception of, and response to, AHLs. While this study is directed at the effects of furanones on the LuxR protein of $V$. fischeri, the findings highlight the potential for the use of halogenated furanones in the control of unwanted bacterial activity. Additionally these results lend support to a model of AHL function in which the metabolite regulates the steady state concentration of LuxR homologues by shielding the regulator from proteolytic degradation.

\section{ACKNOWLEDGEMENTS}

Work on quorum sensing and signal inhibitors was supported by grants from the Danish Medical, Natural and Technical Research Councils and The Danish Plasmid Foundation to M.G. and from the Australian Research Council and the Centre for Marine Biofouling and Bio-Innovation to S. K. We are grateful to Linda Stabell for her technical assistance and to Roger Read and Naresh Kumar for the provision of furanones.

\section{REFERENCES}

Adar, Y. Y., Simaan, M. \& Ulitzur, S. (1992). Formation of the LuxR protein in the Vibrio fischeri lux system is controlled by HtpR through the GroESL proteins. J Bacteriol 174, 7138-7143.

Albus, A. M., Pesci, E. C., Runyen-Janecky, L. J., West, S. E. \& Iglewski, B. H. (1997). Vfr controls quorum sensing in Pseudomonas aeruginosa. J Bacteriol 179, 3928-3935.

Andersen, J. B., Sternberg, C., Poulsen, L. K., Bjørn, S. P., Givskov, M. \& Molin, S. (1998). New unstable variants of green fluorescent protein for studies of transient gene expression in bacteria. Appl Environ Microbiol 64, 2240-2246.

Andersen, J. B., Heydorn, A., Hentzer, M., Eberl, L., Geisenberger, O., Molin, S. \& Givskov, M. (2001). gfp based N-acyl-homoserine- lactone monitors for detection of bacterial communication. Appl Environ Microbiol 67, 575-585.

Bainton, N. J., Bycroft, B. W., Chhabra, S. R. \& 8 other authors (1992). A general role for the $\operatorname{lux}$ autoinducer in bacterial cell signalling: control of antibiotic biosynthesis in Erwinia. Gene 116, 87-91.

Barras, F., van Gijsegem, F. \& Chatterjee, A. K. (1994). Extracellular enzymes and pathogenesis of soft rot Erwinia. Annu Rev Phytopathol 32, 201-234.

Bassler, B. L., Wright, M., Showalter, R. E. \& Silverman, M. R. (1993). Intercellular signaling in Vibrio harveyi: sequence and function of genes regulating expression of luminescence. Mol Microbiol 9, 773-786.

Choi, S. H. \& Greenberg, E. P. (1992). Genetic evidence for the multimerization of LuxR, the transcriptional activator of Vibrio fischeri luminescence. Mol Mar Biol Biotechnol 1, 408-413.

Clark, D. J. \& Maaløe, O. (1967). DNA replication and division cycle in Escherichia coli. J Mol Biol 23, 99-112.

Correa, J. A. (1996). Diseases in seaweeds: an introduction. Hydrobiologia 326, 87-88.

Davies, D. G., Parsek, M. R., Pearson, J. P., Iglewski, B. H., Costerton, J. W. \& Greenberg, E. P. (1998). The involvement of cell-to-cell signals in the development of a bacterial biofilm. Science 280, 295-298.

de Nys, R., Wright, A. D., Konig, G. M. \& Sticher, O. (1993). New halogenated furanones from the marine alga Delisea pulchra (cf. Fimbriata). Tetrahedron 49, 11213-11220.

Dworjanyn, S. A., de Nys, R. \& Steinberg, P. D. (1999). Localisation and surface quantification of secondary metabolites in the red alga Delisea pulchra. Mar Biol 133, 727-736.

Eberhard, A., Burlingame, A. L., Eberhard, C., Kenyon, G. L., Nealson, K. H. \& Oppenheimer, N. J. (1981). Structural identification of autoinducer of Photobacterium fischeri luciferase. Biochemistry 20, 2444-2449.

Eberl, L. (1999). N-Acyl homoserine lactone-mediated gene regulation in Gram-negative bacteria. Syst Appl Microbiol 22, 493-506.

Eberl, L., Molin, S. \& Givskov, M. (1999). Surface motility in Serratia liquefaciens. J Bacteriol 181, 1703-1712.

Fenical, W. (1997). New pharmaceuticals from marine organisms. Trends Biotechnol 15, 339-341.

Fuqua, C. \& Eberhard, A. (1999). Signal generation in autoinduction systems: synthesis of acylated homoserine lactones by LuxItype proteins. In Cell-Cell Signaling in Bacteria, pp. 211-230. Edited by G. M. Dunny \& S. C. Winans. Washington, DC: American Society for Microbiology.

Fuqua, C., Winans, S. C. \& Greenberg, E. P. (1996). Census and consensus in bacterial ecosystems: the LuxR-LuxI family of quorum-sensing transcriptional regulators. Annu Rev Microbiol 50, 727-751.

Givskov, M., de Nys, R., Manefield, M., Gram, L., Maximilien, R., Eberl, L., Molin, S., Steinberg, P. D. \& Kjelleberg, S. (1996). Eukaryotic interference with homoserine lactone mediated prokaryotic signaling. J Bacteriol 178, 6618-6622.

Goloubinoff, P., Gatenby, A. A. \& Lorimer, G. H. (1989). GroE heat-shock proteins promote the assembly of foreign prokaryotic ribulose biphosphate carboxylase oligomers in Escherichia coli. Nature 337, 44-47.

Guyer, M. S., Reed, R. E., Steitz, T. \& Low, K. B. (1981). Identification of a sex-factor-affinity site in E. coli as gamma delta. Cold Spring Harbor Symp Quant Biol 45, 135-140. 
Hanzelka, B. L. \& Greenberg, E. P. (1995). Evidence that the Nterminal region of the Vibrio fischeri LuxR protein constitutes an autoinducer-binding domain. J Bacteriol 177, 815-817.

Jones, S., Yu, B., Bainton, N. J. \& 11 other authors (1993). The lux autoinducer regulates the production of exoenzyme virulence determinants in Erwinia carotovora and Pseudomonas aeruginosa. EMBO J 12, 2477-2482.

Kievit, T. R. \& Iglewski, B. (2000). Bacterial quorum sensing in pathogenic relationships. Infect Immun 68, 4839-4849.

Kjelleberg, S. \& Steinberg, P. (2001). Defences against bacterial colonisation of marine plants. In Phyllosphere Microbiology, pp. 157-172. Edited by S. E. Lindow, E. Hecht-Poinar \& V. Elliot. St Paul, MN: American Phytopathological Society.

Kjelleberg, S., Steinberg, P., Givskov, M., Gram, L., Manefield, M. \& de Nys, R. (1997). Do marine natural products interfere with prokaryotic AHL regulatory systems? Aquat Microbial Ecol 13, 85-93.

Manefield, M., de Nys, R., Kumar, N., Read, R., Givskov, M., Steinberg, P. \& Kjelleberg, S. (1999). Evidence that halogenated furanones from Delisea pulchra inhibit acylated homoserine lactone (AHL)-mediated gene expression by displacing the AHL signal from its receptor protein. Microbiology 145, 283-291.

Manny, A. J., Kjelleberg, S., Kumar, N., de Nys, R., Read, R. W. \& Steinberg, P. (1997). Reinvestigation of the sulfuric acid-catalysed cyclisation of brominated 2-alkyllevulinic acids to 3-alkyl-5methylene-2 $(5 H)$-furanones. Tetrahedron 53, 15813-15826.

McClean, K. H., Winson, M. K., Fish, L. \& 9 other authors (1997). Quorum sensing and Chromobacterium violaceum: exploitation of violacein production and inhibition for the detection of $\mathrm{N}$ acylhomoserine lactones. Microbiology 143, 3703-3711.

Nealson, K. H., Eberhard, A. \& Hastings, J. W. (1972). Catabolite repression of bacterial bioluminescence: functional implications. Proc Natl Acad Sci US A 69, 1073-1076.

Piper, K., Beck von Bodman, S. \& Farrand, S. K. (1993). Conjugation factor of Agrobacterium tumefaciens regulates $\mathrm{Ti}$ plasmid transfer by autoinduction. Nature 362, 448-450.

Qin, Y., Luo, Z., Smyth, A. J., Gao, P., Beck von Bodman, S. \& Farrand, S. K. (2000). Quorum-sensing signal binding results in dimerization of TraR and its release from membranes into the cytoplasm. EMBO J 19, 5212-5221.

Rasmussen, T. B., Manefield, M., Andersen, J. B., Eberl, L., Anthoni, U., Christophersen, C., Steinberg, P., Kjelleberg, S. \& Givskov, M. (2000). How Delisea pulchra furanones affect quorum sensing and swarming motility in Serratia liquefaciens MG1. Microbiology 146, 3237-3244.

Rodelas, B., Lithgow, J. K., Wisniewski-Dye, F., Hardman, A., Wilkinson, A., Economou, A., Williams, P. \& Downie, J. A. (1999). Analysis of quorum-sensing-dependent control of rhizosphereexpressed (rhi) genes in Rhizobium leguminosarum bv. viciae. J Bacteriol 181, 3816-3823.

Sitnikov, D. M., Schineller, J. B. \& Baldwin, T. O. (1995). Transcriptional regulation of bioluminesence genes from Vibrio fischeri. Mol Microbiol 17, 801-812.

Swift, S., Williams, P. \& Stewart, G. S. A. B. (1999). N-Acylhomoserine lactones and quorum sensing in proteobacteria. In CellCell Signaling in Bacteria, pp. 291-313. Edited by G. M. Dunny \& S. C. Winans. Washington DC: American Society for Microbiology.

Ulitzur, S., Matin, A., Fraley, C. \& Meighen, E. (1997). H-NS protein represses transcription of the lux systems of Vibrio fischeri and other luminous bacteria cloned into Escherichia coli. Curr Microbiol 35, 336-342.

Welch, M., Todd, D. E., Whitehead, N. A., McGowan, S. J., Bycroft, B. A. \& Salmond, G. P. C. (2000). N-acyl homoserine lactone binding to the CarR receptor determines quorum-sensing specificity in Erwinia. EMBO J 19, 631-641.

Wells, P. R. (1963). Enol lactones of dibromoacetylacrylic acid. Aust J Chem 16, 165-169.

Zhang, L., Murphy, P. J., Kerr, A. \& Tate, M. E. (1993). Agrobacterium conjugation and gene regulation by $\mathrm{N}$-acyl-L-homoserine lactones. Nature 362, 446-448.

Zhu, J. \& Winans, S. C. (1999). Autoinducer binding by the quorum-sensing regulator TraR increases affinity for target promoters in vitro and decreases TraR turnover rates in whole cells. Proc Natl Acad Sci US A 96, 4832-4837.

Zhu, J. \& Winans, S. C. (2001). The quorum-sensing transcriptional regulator TraR requires its cognate signaling ligand for protein folding, protease resistance, and dimerization. Proc Natl Acad Sci U S A 98, 1507-1512.

Zhu, J., Beaber, J. W., More, M. I., Fuqua, C., Eberhard, A. \& Winans, S. C. (1998). Analogs of the autoinducer 3-oxooctanoylhomoserine lactone strongly inhibit activity of the TraR protein of Agrobacterium tumefaciens. J Bacteriol 180, 5398-5405.

Received 2 July 2001; revised 7 December 2001; accepted 19 December 2001. 